\title{
Penerapan Metode Weight Product (WP) Untuk Menentukan Pengalokasian Pendistribusian Telur Terbaik Di Kecamatan Pantai Labu
}

\author{
Prawita Ardella ${ }^{1 *}$, Paska Marto Hasugian ${ }^{2}$ \\ ${ }^{1,2}$ STMIK Pelita Nusantara \\ Alamat Jl. Iskandar Muda No. 1 Medan 20154 Indonesia \\ Corresponding author's e-mail: prawitaardela@gmail.com
}

\begin{abstract}
Abstrak - Pendistribusian merupakan hal yang penting dalam kegiatan bisnis, terutama untuk perusahaan distribusi atau distributor. Keterlambatan distribusi akan menurunkan tingkat layanan pelanggan. Metode yang digunakan adalah WP (Weighted Product), karena Weighted product merupakan salah satu pilihan metode yang tepat untuk menyelesaikan masalah-masalah yang kompleks dan Weighted Product bisa menghasilkan perhitungan yang terstruktur pada masalah yang memiliki sub-sub pada kriteria keputusan yang akan dibangun.Tujuan dari penelitian ini ialah menentukan lokasi pendistribusian telur terbaik di kecamatan pantai labu dengan menggunakan metode Weighted Product (WP). Metode Weighted Product (WP) adalah keputusan analisis multi-kriteria dan merupakan metode pengambilan keputusan multi kriteria. WP adalah himpunan dari alternatif keputusan yang dijelaskan dalam istilah beberapa kriteria. Dalam metode WP tidak diperlukan manipulasi matriks karena metode ini mengalikan hasil penilaian setiap atribut. Hasil penelitian berdasarkan hasil perangkingan pada menggunakan metode Weighted Product (WP) untuk menentukan lokasi pendistribusian terbaik Di Kecamatan Pantai Labu, maka nilai terbesar adalah Grosir 2 dengan nilai 0.2309 dapat dipilih menjadi lokasi pendistribusian terbaik. bobot agar dapat digunakan dengan metode tersebut. Kata kunci: lokasi distribusi, bobot, Weight Product, SPK
\end{abstract}

Abstract - Distribution is an important thing in business activities, especially for distribution companies or distributors. Delays in distribution will reduce customer service levels. The method used is WP (Weighted Product), because Weighted product is one of the right choice of method to solve complex problems and Weighted Product can produce structured calculations on problems that have sub-sub-criteria for the decision to be built. from this research is to determine the best egg distribution location in the pumpkin beach district using the Weighted Product (WP) method. The Weighted Product (WP) method is a multi-criteria analysis decision and is a multi-criteria decision-making method. WP is a set of alternative decisions described in terms of several criteria. In the WP method there is no need for matrix manipulation because this method multiplies the assessment results of each attribute. The results of the research are based on the results of the ranking using the Weighted Product (WP) method to determine the best distribution location in the pumpkin beach district, so the greatest value is Grosir 2 with a value of 0.2309 which can be chosen to be the best distribution location. weights so that they can be used with that method.

Keywords: distribution location, weight, Weight Product, SPK,

\section{Pendahuluan}

Pemilihan lokasi pendistribusain merupakan salah satu hal terpenting yang mendukung penjualan. Apabila suatu usaha ingin meningkatkan tingkat penjualan, maka perlu mengatur strategi pemilihan lokasi agar dapat memiliki daya saing. Pemilihan lokasi dapat dilakukan dengan banyak cara, salah satunya adalah memperluas pemasaran dengan membuka cabang usaha tersebut ditempat yang berbeda. Dengan adanya banyak cabang, maka para pembeli atau konsumen akan lebih mudah mendapatkan produk oleh-oleh dimana saja. Dalam menentukan lokasi pemasaran, pemilik usaha harus memperhatikan beberapa atau beberapa faktor atau kriteria seperti jarak lokasi pemasaran dengan pusat kota atau objek wisata, dan banyak faktor lainnya, oleh karena itu, diperlukan sistem pendukung keputusan agar memudahkan perusahaan dalam menentukan lokasi pendistribusian terbaik[1]. Sistem pendukung keputusan untuk menentukan lokasi pendistribusian terbaik adalah sebuah alternatif untuk membantu pengambilan keputusan dalam proses pemilihan lokasi pendistibusian telur di kecamatan pantai labu. Dengan adanya penerapan sistem pendukung keputusan diharapkan dapat membantu usaha penjualan telur di kecamatan pantai labu untuk menentukan lokasi pemasaran produk sehingga dapat meningkatkan penjualan usaha. Selain itu hasil penelitian adalah lokasi terbaik yang tepat untuk memasarkan produk usaha berdasarkan perhitungan yang telah dilakukan. menggunakan data dan model untuk memecahkan masalah dengan menggunakan metode Weighted Product (WP) [2].

Metode Weighted Product merupakan metode penentuan dalam sebuah keputusan dengan cara perkalian untuk dapat menghubungkan nilai atribut, dimana nilai atribut harus dipangkatkan terlebih dahulu dengan 
bobot atribut yang bersangkutan [3]. Metode ini sangat cocok untuk menentukan lokasi pendistribusian telur di pantai labu dengan dapat menentukan sendiri bobot kepentingan dari masing-masing kriteria, untuk mencari nilai prefensi dan perangkingan setiap alternatif yang dapat memudahkan dalam menentukan lokasi pendistribusian terbaik yang dapat menjadi sarana penunjang bagi pengambilan keputusan [4].

Penelitian berjudul wetode Weightd Product (WP) Dalam Sistem Pendukung Keputusan Penerimaan Beasiswa Prestasi menjelaskan Metode WP dipilih karena mampu menyeleksi alternatif terbaik dari sejumlah alternatif dan keunggulannya dalam teknik pembobotan. Sistem ini dirancang menggunakan bahasa pemrograman visual VB.Net dan MySQL sebagai database [5]. Sistem ini dapat melakukan pemeringkatan terhadap siswa dengan menghitung bobot kriteria. Alternatif yang digunakan dalam penelitian ini berdasarkan rata-rata nilai hasil belajar, persentase kehadiran, penghasilan orang tua, serta jumlah tanggungan orang tua. Penelitian berjudul Penerapan Metode Weight Product Pada Penentuan Penerimaan Karyawan menguraikan Penelitian ini menggunakan metode Weight Product untuk memberi kemudahan dalam penentuan penerimaan karyawan pada Koperasi Pedagang Pasar Indonesia (KOPPI) Sorong Provinsi Papua Barat. Tahapan penelitian dilakukan dengan identifikasi masalah, studi literatur, pengumpulan data, metode WP, menentukan kriteria, menentukan bobot, mengolah data perhitungan dan kesimpulan [6]. Perangkingan dilakukan berdasar standar nilai untuk diterimanya calon karyawan. Penelitian ini ditentukan dengan 5 kriteria, yaitu ijazah, skill, motivation letter, etos kerja dan dapat dipercaya dengan 8 sampel data pelamar [7].

Penelitian Sistem Pendukung Keputusan Dalam Menentukan Kualitas Jambu Biji Unggulan Menggunakan Metode Weighted Product menjelaskan metode weighted product merupakan metode pengambilan keputusan dengan cara perkalian untuk menghubungkan rating atribut, dimana rating setiap atribut harus dipangkatkan dulu dengan bobot atribut yang bersangkutan. Pada dasarnya metode weighted product merupakan bagian dari konsep Fuzzy Multiple Attribute Decision Making yang merupakan suatu metode untik mencari alternative optimal dari sejumlah alternative dengan criteria tertentu [8] [9].

\section{Tinjauan Pustaka}

\subsection{Metode Weighted Product (WP}

Metode Weighted Product (WP) adalah keputusan analisis multi-kriteria dan merupakan metode pengambilan keputusan multi kriteria [10]. Seperti semua metode-metode lainanya, WP adalah himpunan dari alternatif keputusan yang dijelaskan dalam istilah beberapa kriteria. Metode perkalian atau metode WP ini berbeda dengan metode SAW dalam perlakuan awal terhadap hasil penilaian atribut keputusan. Dalam metode WP tidak diperlukan manipulasi matriks karena metode ini mengalikan hasil penilaian setiap atribut. Hasil perkalian tersebut belum dibandingkan (dibagi) dengan nilai standar, dalam hal ini alternatif ideal sering digunakan sebagai nilai standar bobot, Bobot untuk atribut manfaat berfungsi sebagai pangkat positif dalam proses perkalian antar atribut, sementara bobot berfungsi sebagai pangkat negatif [11] [12].

\subsection{Langkah-langkah metode Weihted Product (WP)}

Langkah-langkah dalam menggunakan metode WP sebagai berikut [13] [14]:

a. Menentukan kriteria-kriteria yang akan dijadikan acuan dalam pengambilan keputusan

b. Menentukan rating kecocokan setiap alternatif pada setiap kriteria.

c. Menentukan bobot preferensi(w) tiap kriteria, sebagai berikut.

$$
W_{j=\frac{W j}{\sum^{W}}}
$$

d. Mengalikan seluruh atribut bagi sebuah alternatif dengan bobot sebagai pangkat positif untuk atribut keuntungan dan bobot berpangkat negatif untuk atribut biaya.

$S_{i}=\prod_{J}^{n}=1 X_{i j w \mathrm{j}} \ldots \ldots \ldots . .(2)$

e. Hasil perkalian tersebut dijumlahkan untuk menghasilkan nilai V untuk setiap alternatif. Preferensi relatif dari setiap alternatif, diberikan sebagai.

$V_{i}=\frac{\prod_{J}^{n}=1 X_{i j w_{j}}}{\prod_{J}^{n}=1\left(X_{j *}\right) \dot{w} j}$.

f. Mencari nilai alternatif dengan melakukan langkah yang sama seperti pada langkah satu, hanya saja menggunakan nilai tertinggi untuk setiap atribut tertinggi untuk setiap atribut manfaat dan nilai terendah untuk atribut biaya.

g. Membagi nilai $\mathrm{V}$ bagi setiap alternatif dengan nilai standar $\left(\mathrm{V}\left(\mathrm{A}^{*}\right)\right)$ yang menghasilkan $\mathrm{R}$

h. Mencari nilai alternatif ideal.

\section{Metode Penelitian}

Sistem yang dihasilkan akan berkulaitas baik dikarenakan pelaksanaannya secara bertahap. Tahapan dari Metode Waterfall adalah seperti pada gambar berikut : 


\section{Hasil dan Pembahasan}

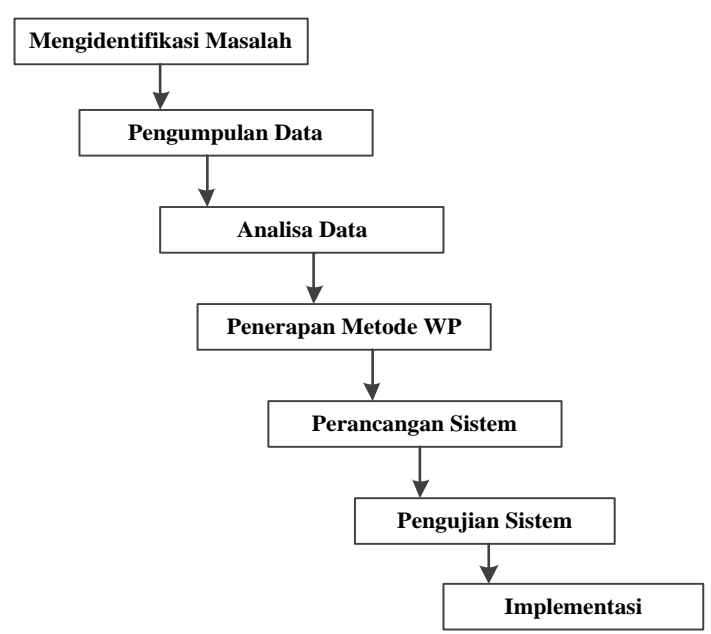

Gambar 1. Metode Waterfall

Sistem pendukung keputusan menentukan pendistribusian telur terbaik di Kecamatan Pantai Labu menggunakan metode WP. Weighted Product (WP) adalah suatu proses untuk membantu dalam menentukan keputusan, konsep yang digunakan adalah dengan pembobotan rating suatu variabel penilai. Data penilaian didapat dari masing-masing kriteria, lalu dibuat suatu tingkat kepentingan kriteria berdasarkan nilai bobot yang ditentukan ke dalam bilangan fuzzy. Rating kecocokan setiap alternatif pada setiap kriteria adalah Sangat Buruk $=1$ Buruk $=2$ Cukup $=3$ Baik $=4$ Sangat Baik $=5$.

Kriteria dan rating kecocokan setiap alternatif yang telah ditentukan, selanjutnya diberikan nilai / bobot setiap alternatif pada setiap kriteria yang telah ditentukan.

1. Kriteria kepadatan penduduk (C1)

Kriteria kepadatan penduduk dilihat dari lokasi yang akan di pilih sebagai tempat pendistribusian telur terbaik.

2. Jarak dari pemukiman (C2)

Kriteria jarak dari pemukiman dilihat dari lokasi yang akan di pilih sebagai tempat pendistribusian telur terbaik.

3. Kriteria Potensi Pasar (C3)

Kriteria prestasi kerja dilihat dari lokasi yang akan di pilih sebagai tempat pendistribusian telur terbaik.

4. Kriteria Jalur Transportasi(C4)

Kriteria loyalitas dilihat dari lokasi yang akan di pilih sebagai tempat pendistribusian telur terbaik.

5. Kriteria Harga Sewa (C5)

Kriteria tanggung jawab dilihat dari lokasi yang akan di pilih sebagai tempat pendistribusian telur terbaik.

Nilai dari setiap kriteria merupakan hasil penginputan data alternatif lokasi pendistribusian telur yang sudah di konversikan berdasarkan bobot kriteria yang sudah ditentukan melalui proses perhitungan.

Tabel 1. Data Alternatif

\begin{tabular}{|c|c|c|c|c|c|}
\hline \multirow{2}{*}{$\begin{array}{c}\text { Kode } \\
\text { Alternatif }\end{array}$} & $\begin{array}{c}\text { Kepadatan } \\
\text { Penduduk }\end{array}$ & $\begin{array}{c}\text { Jarak dari } \\
\text { Pemukiman }\end{array}$ & $\begin{array}{c}\text { Potensi } \\
\text { Pasar }\end{array}$ & $\begin{array}{c}\text { Jalur } \\
\text { Transfortasi }\end{array}$ & Harga Sewa \\
\cline { 2 - 6 } A1 & $\begin{array}{c}\text { Jumlah penduduk } \\
\text { sedikit }\end{array}$ & Sedang & Lumayan & $\begin{array}{c}\text { Merupakan } \\
\text { Jalur Umum }\end{array}$ & $25-30$ juta \\
\hline A2 & $\begin{array}{c}\text { Jumlah penduduk } \\
\text { banyak }\end{array}$ & Sangat Dekat & $\begin{array}{c}\text { Sangat } \\
\text { Dekat }\end{array}$ & $\begin{array}{c}\text { Lebar Jalan } \\
\text { Memadai }\end{array}$ & $<20$ juta \\
\hline A3 & $\begin{array}{c}\text { Jumlah penduduk } \\
\text { banyak }\end{array}$ & Lumayan & Lumayan & $\begin{array}{c}\text { Terdapat Jalur } \\
\text { Alternatif }\end{array}$ & $25-30$ juta \\
\hline A4 & $\begin{array}{c}\text { Jumlah penduduk } \\
\text { sedikit }\end{array}$ & Lumayan & Lumayan & $\begin{array}{c}\text { Lebar Jalan } \\
\text { Memadai }\end{array}$ & $>50$ juta \\
\hline A5 & $\begin{array}{c}\text { Jumlah penduduk } \\
\text { sedikit }\end{array}$ & Jauh & Lumayan & $\begin{array}{c}\text { Terdapat Jalur } \\
\text { Alternatif }\end{array}$ & $<15$ juta \\
\hline
\end{tabular}

Tabel 2. Data Kecocokan Alternatif 


\begin{tabular}{|c|c|c|c|c|c|}
\hline \multirow{2}{*}{$\begin{array}{c}\text { Kode } \\
\text { Alternatif }\end{array}$} & $\begin{array}{c}\text { Kriteria } \\
\text { Pepadatan }\end{array}$ & $\begin{array}{c}\text { Jarak dari } \\
\text { Pemukiman }\end{array}$ & $\begin{array}{c}\text { Potensi } \\
\text { Pasar }\end{array}$ & $\begin{array}{c}\text { Jalur } \\
\text { Transfortasi }\end{array}$ & Harga Sewa \\
\hline A1 & 1 & 3 & 3 & 1 & 3 \\
\hline A2 & 4 & 5 & 5 & 4 & 4 \\
\hline A3 & 4 & 3 & 3 & 3 & 3 \\
\hline A4 & 2 & 3 & 3 & 4 & 3 \\
\hline A5 & 2 & 2 & 3 & 3 & 5 \\
\hline
\end{tabular}

Setelah ditentukan kriteria dan bobot, dicari kriteria mana yang bernilai keuntungan dan biaya. Jika bernilai keuntungan maka nilai atribut tersebut tetap ( positif ) dan jika bernilai biaya maka akan berubah menjadi negatif. Pada contoh kasus di atas semua atribut bernilai positif. Sebelummya dilakukan perbaikan bobot terlebih dahulu maka pangkat diperoleh dari jumlah w dibagi masing-masing nilai dari kriteria yang sudah ditentukan dengan rumus.

1. Menentukan bobot untuk masing-masing kriteria

$$
\sum W_{j}=0.2353+0.2353+0.1765+0.1765+0.1765=1
$$

Maka setelah menentukan nilai w dari masing - masing kriteria, selanjutnya dilakukan perbaikan bobot

2. Menentukan nilai vektor $\mathrm{S}$

$$
\begin{aligned}
& \text { SA1 }=\left(1^{0.24}\right) *\left(3^{0.24}\right) *\left(3^{0.18}\right) *\left(1^{0.18}\right) *\left(3^{0.18}\right)=1.9084 \\
& \text { SA2 }=\left(4^{0.24}\right) *\left(5^{0.24}\right) *\left(5^{0.18}\right) *\left(4^{0.18}\right) *\left(4^{0.18}\right)=2.2837 \\
& \text { SA3 }=\left(4^{0.24}\right) *\left(3^{0.24}\right) *\left(3^{0.18}\right) *\left(3^{0.18}\right) *\left(3^{0.18}\right)=1.6718 \\
& \text { SA4 }=\left(2^{0.24}\right) *\left(3^{0.24}\right) *\left(3^{0.18}\right) *\left(4^{0.18}\right) *\left(3^{0.18}\right)=2.0705 \\
& \text { SA5 }=\left(2^{0.24}\right) *\left(2^{0.24}\right) *\left(3^{0.18}\right) *\left(3^{0.18}\right) *\left(5^{0.18}\right)=1.9577
\end{aligned}
$$

3. Menentukan nilai vector $\mathrm{V}$ merupakan prefrensi untuk alternatif

\begin{tabular}{l} 
VA1 $=\frac{1.9084}{1.9084+2.837+1.6718+2.0705+1.9577}=\frac{1.9084}{9.892}=0.1929$ \\
VA2 $=\frac{2.2837}{1.9084+2.837+1.6718+2.0705+1.9577}=0.2309$ \\
VA3 $=\frac{1,6718}{1.9084+2.837+1.6718+2.0705+1.9577}=\frac{1.6718}{9.9892}=0.169$ \\
VA4 $=\frac{2.0705}{1.9084+2.837+1.6718+2.0705+1.9577}=\frac{1.9577}{9.892}=0.2093$ \\
VA5 $=\frac{1.9577}{1.9084+2.837+1.6718+2.0705+1.9577}=0.1979$ \\
\hline Tabel 3. Hasil Perangkingan
\end{tabular}

Berdasarkan hasil perangkingan pada tabel 3 menggunakan metode Weighted Product (WP) untuk menentukan lokasi pendistribusian telur terbaik di kecamatan pantai labu, maka nilai terbesar adalah Grosir 2 dengan nilai 0.2309 dapat dipilih menjadi lokasi pendistribusian terbaik.

Implementasi sistem merupakan tahapan dalam menerapkan sistem yang telah dibangun, dimana nantinya akan diketahui kualitas dari sistem yang dirancang, pakah sudah dapat berjalan dengan baik dan sesuai dengan tujuan yang diharapkan. Dalam melakukan implementasi dipersiapkan beberapa sarana yang berhubungan dengan perangkat keras (hardware) dan peerangkat lunak (software).Implementasi antarmuka merupakan rancangan antarmuka yang akan digunakan sebagai perantara user dengan perangkat lunak yang digunakan implementasi antarmuka dari perancangan aplikasi berbasis web dari Penerapan Metode Weight Produc Untuk Menentukan Menentukan Lokasi Pendistribusian Telur terbaik di Kecamatan Pantal Labu adalah sebagai berikut pada Halaman analisis perhitungan WP merupakan halaman yang digunakan admin untuk melihat hasil perhitungan metode Weight Product dari haisl input halaman alternatif. 


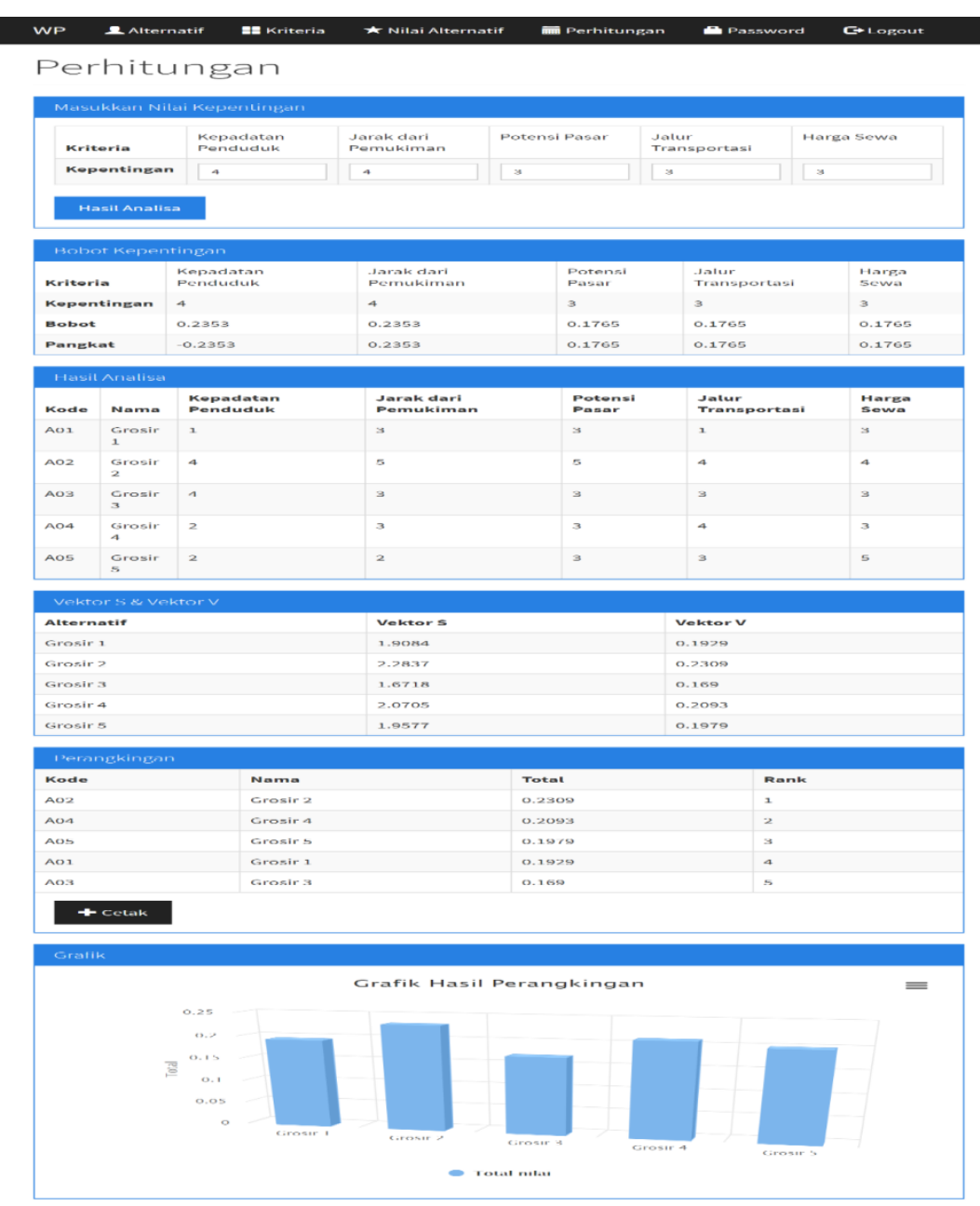

\section{Kesimpulan}

Gambar 2. Tampilan Perhitungan Weight Product

Kesimpulan dari penelitian :

1. Penerapan Metode Weight Product (WP) untuk menentukan lokasi pendistribusian telur terbaik digunakan sebagai sarana pendukung keputusan dengan menyesuaikan kriteria dan menggunkan bobot agar dapat digunakan dengan metode tersebut.

2. Aplikasi yang dirancang dapat memberikan informasi pemilihan lokasi pendistribusian telur terbaik dengan kriteria yang sudah ditentukan.

3. Aplikasi penerapan metode Weight Product (WP) di implementasikan digunakan sebagai sarana pendukung keputusan pemilihan lokasi pendistribusian telur terbaik di kecamatan pantai labu.

\section{Daftar Pustaka}

[1] A. E. Silitonga and A. Simangunsong, "Sistem Pendukung Keputusan Dalam Menentukan Penerima Bantuan Langsung Tunai Dengan Metode Profile Matching Pada Kantor Kepala Desa Narigunung 1," $J$. Nas. Komputasi dan Teknol. Inf., vol. 3, no. 3, pp. 275-280, 2020.

[2] E. Ermin, S. Sunardi, and A. Fadlil, "Penerapan Metode Weight Product Pada Penentuan Penerimaan Karyawan," Cybernetics, vol. 4, no. 01, p. 9, 2020.

[3] M. Fauzi, "Penerapan Metode Weight Product Untuk Sistem Pendukung Keputusan Pemilihan Pemasok Alat Musik Pada Studio Musik Enterprise," J. Tek. Inform. Kaputama, vol. 2, no. 1, pp. 98-104, 2018.

[4] R. Fitria and S. N. Rakhmah, "Penerapan Metode Weighted Product Untuk Menganalisis Faktor Pemilihan Pembayaran Digital Transaction Pada Aplikasi Ojek Online," J. Tek., vol. 11, no. 2, p. 1098, 2019.

[5] D. M. Khairina, D. Ivando, and S. Maharani, "Implementasi Metode Weighted Product Untuk Aplikasi Pemilihan Smartphone Android," J. INFOTEL - Inform. Telekomun. Elektron., vol. 8, no. 1, p. 16, 2016. 
[6] F. Laila and A. Sindar, "Penentuan Supplier Bahan Baku Restaurant XO Suki Menggunakan Metode Weight Product," vol. 2, no. April, pp. 1-4, 2019.

[7] D. Lestari and A. S. R. Sinaga, "Penentuan Karyawan Kontrak Menjadi Karyawan Tetap PT. Timbang Deli Dengan Metode Analitycal Hierarchy Process (AHP)," J. Teknol., vol. 8, no. 2, pp. 27-37, 2018.

[8] F. Mahardika, U. Ummiyati, and M. Martanto, "Sistem Pendukung Keputusan Menggunakan Metode WP (Weight Product) Pemilihan Minat Jurusan," J. ICT Inf. Commun. Technol., vol. 16, no. 2, pp. 53-57, 2017.

[9] A. R. S. Manik, B. Nurhadiyono, and Y. Rahayu, "Implementasi Metode Weighted Product ( WP ) dalam Sistem Pendukung Keputusan untuk Menyeleksi Penerima Beras Masyarakat Miskin ( Raskin )," Techno.COM, vol. 14, no. 2, pp. 109-114, 2015.

[10] Nurul Putri Utami, Hasanul Fahmi, and Anita Sindar, "Spk Penentuan Pemberian Pinjaman Kepada Anggota Bumdes Dengan Metode Simple Additive Weighting," SINTECH (Science Inf. Technol. J., vol. 2, no. 2, pp. 124-130, 2019.

[11] N. Pakaya and Amiruddin, "Pemuda Nusantara Dengan Menggunakan Metode," Ilk. J. Ilm., vol. 9, no. 3, pp. 331-337, 2017.

[12] F. Susanto, P. T. Informatika, L. Utara, A. Sherly, N. Sari, and A. Salim, "Sistem Pendukung Keputusan Dalam Menentukan Kualitas Jambu Biji Unggulan Menggunakan Metode Weighted Product," vol. 01, no. 03, 2018.

[13] A. Wedhasmara and R. Efendi, "Implementasi Metode Weighted Product Dalam Sistem Pendukung Keputusan Pemilihan Lokasi Tempat Pembuangan Akhir," J. Sist. Inf., vol. 8, no. 1, pp. 2355-4614, 2016.

[14] D. C. Yoni and H. Mustafidah, "Penerapan Metode WP (Weighted Product) Untuk Pemilihan Mahasiswa Lulusan Terbaik di Fakultas Teknik Universitas Muhammadiyah Purwokerto," Juita, vol. IV, no. 1, pp. 22-27, 2016. 